\title{
Mallet Deformity of Distal Phalanx of Index Finger after Snake Bite
}

\author{
Hee Yong Kang, Eun Soo Park, Seung Min Nam \\ Department of Plastic and Reconstructive Surgery, Soonchunhyang University Bucheon Hospital, Bucheon, Korea
}

\begin{abstract}
Snakebites, though uncommon, are a potentially serious cause of disability or death. Snakebites present as puncture wounds or scratches. Local symptoms may include pain, edema, or ecchymosis that may progress to skin necrosis or compartment syndrome. This study explores the case of a 48-year-old male patient bitten by a snake on the distal dorsum of his left index finger. At first examination, the injured finger was markedly swollen. The acute treatment undertaken at the local hospital was to remove the blood blister. One month later, the patient visited Soonchunhyang University Bucheon Hospital and presented with necrotic changes in the skin; an X-ray of the hand demonstrated mallet deformity. His tendinous mallet finger was treated using a modification of the internal suture technique. Photographic images were taken before and after the operation. After the operation, a complete treatment of the skin defect and mallet finger lesion was achieved. The patient tolerated the treatment well with minimal pain.
\end{abstract}

Keywords: Snake bite; Hand deformities, acquired; Snake bites

\section{Introduction}

A snakebite is a traumatic injury induced by various species of snakes. After the trauma, a variety of clinical courses may be observed in patients, from localized symptoms such as pain, swelling, infection, delayed wound healing and tissue necrosis at the injury site, to systemic complications including acute kidney failure, acute respiratory failure, myocardial infarction, disseminated intravascular coagulation, coma, and death [1]. Particularly in South Korea, distal areas of upper extremities are the predominant sites of snakebite injuries [2]. Various severe complications in hands have been reported, including compartment syndrome, sometimes resulting in amputation. Given the importance of the functions of extremities, even localized symptoms of snakebites on extremities should be treated with utmost care.

In the current study, we present a case of tendon trauma caused by snakebite on the left index finger, a type of tendon trauma that has not been reported in previous studies. We believe this study will contribute to improved treatment of snakebite-induced soft tissue damage and tendon trauma. The study was performed in accordance with the principles of the Declaration of Helsinki. The patient provided written informed consent for the publication and the use of his images.

\section{Case}

An otherwise healthy 48-year-old male patient was bitten on the distal dorsum of his left index finger by a snake of unknown species while he was examining wild plants in the mountains 3 weeks before treatment. At the time of initial examination at a local

Case Report

Received: June 12, 2019

Revised: July 18, 2019

Accepted: July 19, 2019

Corresponding author:

Eun Soo Park, M.D., Ph.D.

Department of Plastic and Reconstructive Surgery, Soonchunhyang University Bucheon Hospital, 170 Jomaru-ro, Wonmi-gu, Bucheon 14584, Korea

Tel: +82-32-621-5319

Fax: +82-32-621-5016

E-mail: peunsoo@schmc.ac.kr

This work was supported by the Soonchunhyang University Research Fund.
\end{abstract}

This is an Open Access article distributed under the terms of the Creative Commons Attribution Non-Commercial License (http://creativecommons.org/licenses/by-nc/4.0/) which permits unrestricted non-commercial use, distribution, and reproduction in any medium, provided the original work is properly cited.

C) 2019 Korean Wound Management Society 

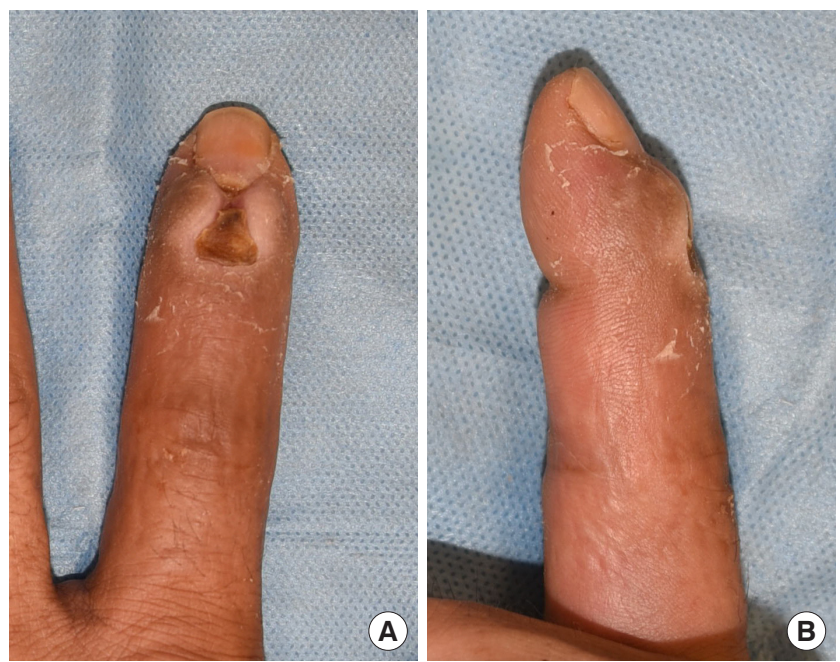

Fig. 1. Preoperative photographic finding. (A) Anteroposterior and $(B)$ lateral view.

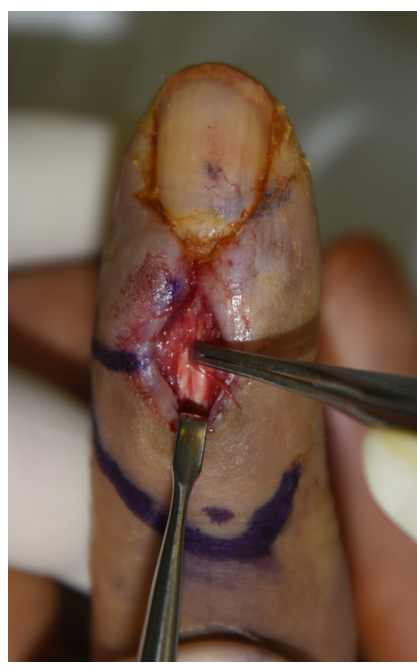

Fig. 3. Intraoperative photograph. Forceps tip indicates torn lesion of extensor tendon.
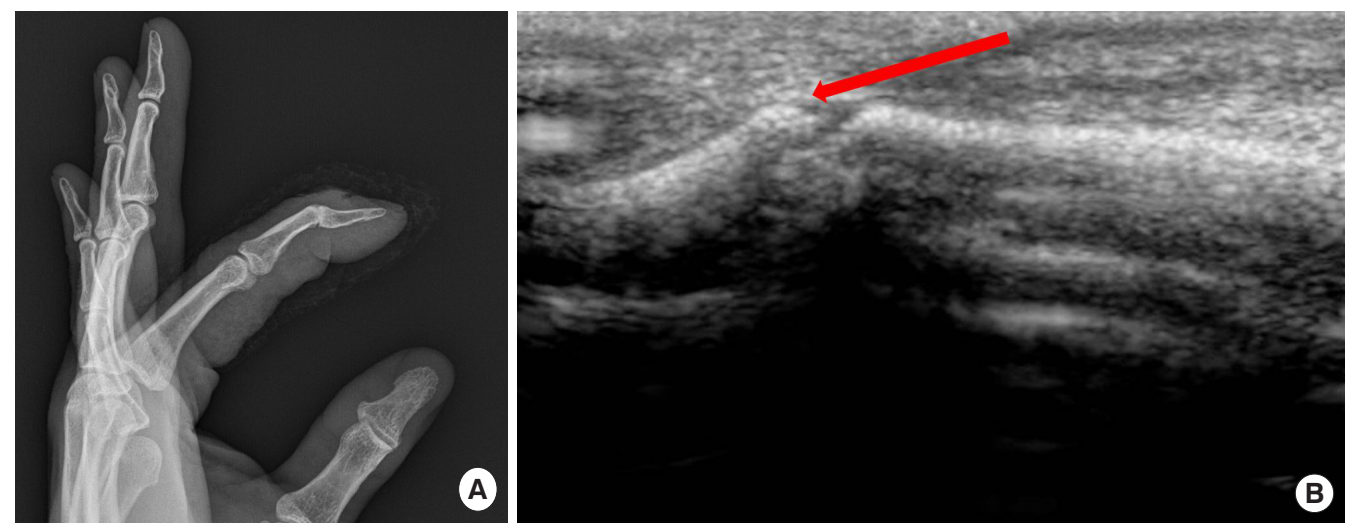

Fig. 2. Preoperative imaging studies. (A) X-ray (lateral view). (B) Ultrasonography showing complete tear of extensor tendon at distal interphalangeal joint of index finger (arrow).

hospital, the injured finger was markedly inflamed (i.e., swollen and red). He was treated with wound dressing using Betadine and oral antibiotics. While in the hospital for acute treatment, a blood blister was also debrided. Two weeks after discharge, the patient visited the local hospital's outpatient clinic for follow-up, and was referred to our institute for further surgical debridement of epidermolysis. After receiving surgical debridement of focal necrotic tissue and wound dressing at our outpatient clinic, the patient did not return until 1 month later, when he presented to our hospital with necrotic changes in the skin and mallet deformity of the impaired finger (Fig. 1). $\mathrm{X}$-rays (Fig. 2A) and ultrasonography (Fig. 2B) were used to investigate the mallet deformity. After this examination, we decided to operate under general anesthesia to correct the mallet deformity. In the surgery, dry eschar tissue was re- moved by making a vertical incision. Exploration of the tissue structure using mosquito forceps and Metzenbaum scissors revealed total rupture of extensor tendon on the distal interphalangeal joint area (Fig. 3). The mallet finger of tendinous origin was treated using Mitek anchor and modified protocol of the internal suture technique [3]. The internal suture technique presented in this case employed two nonabsorbable sutures passing through two oblique holes drilled in the base of the distal phalanx (Fig. 4B). Because the sutures passed back along the periosteum of the distal phalanx, we were able to catch the bone for fixation. Employing the full-thickness skin graft technique, we covered the center portion of the defect of the distal phalanx with a local transposition flap from the middle phalanx tissue (Fig. 4).

After discharge, the wound was dressed twice at the outpa- 

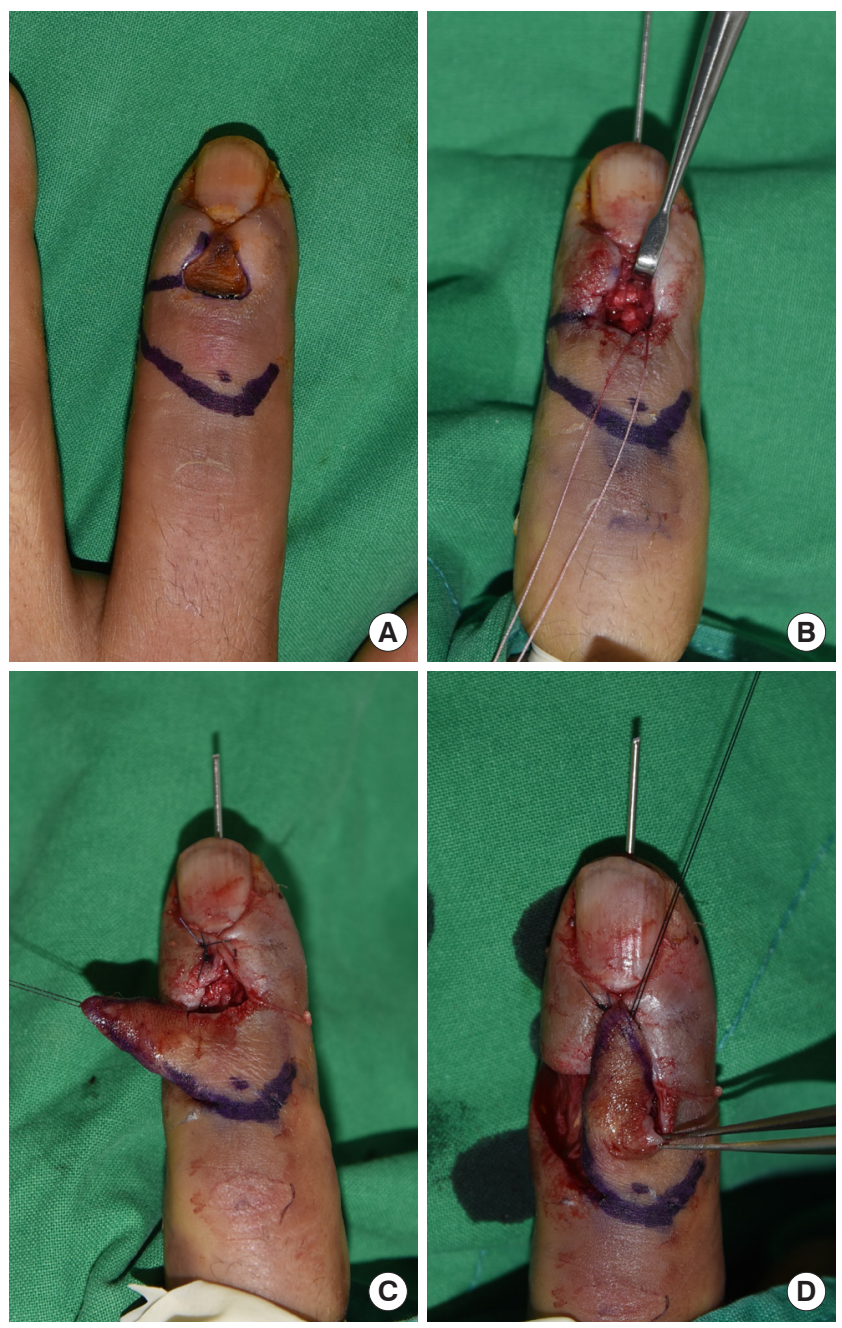

Fig. 4. Intraoperative photographs. (A) Design of local transposition flap. (B) Tendon was fixated by Mitek anchor and internal suture technique. (C) Elevation of local transposition flap. (D) Inset of local transposition flap.

tient department and was diagnosed to have achieved total healing at postoperative day 21 (Fig. 5). A finger splint was applied for 6 weeks after the operation.

\section{Discussion}

There are some studies describing snakebite envenomation as the cause of various musculoskeletal system diseases such as arthritis, osteomyelitis, muscle necrosis and also amputation of extremities. However, there is a dearth of literature detailing the species of snakes involved, and the epidemiology, disease course and prognosis of musculoskeletal disorders by snakebites $[4,5]$. In particular, chronic mallet deformities caused by snakebites have not been explored in research yet, partially
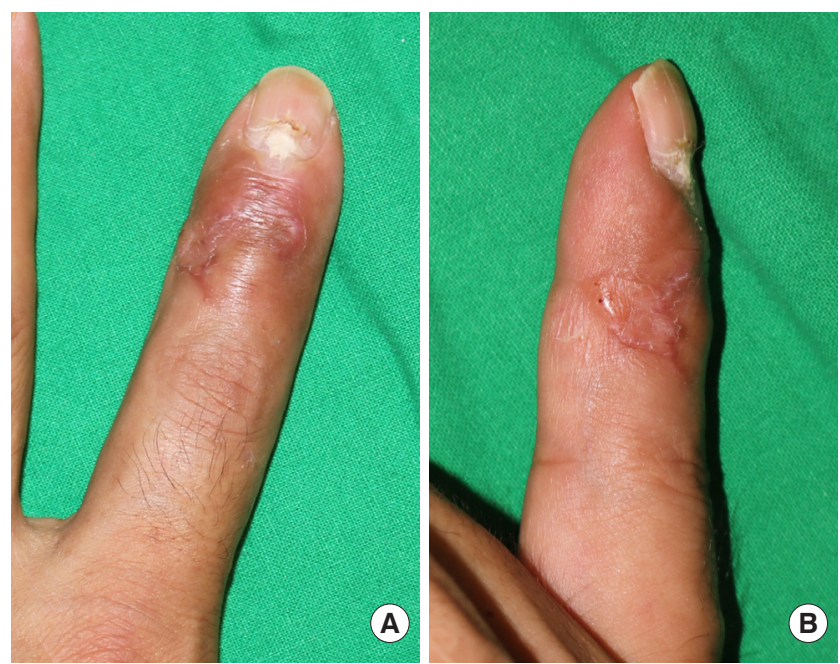

Fig. 5. Postoperative photographic findings after 2 months. (A) Anteroposterior and (B) lateral view.

owing to the low incidence of snakebites in modern life.

Although we did not observe the initial course of the patient, we presume that his mallet deformity progressed gradually. The medical referral document sent by the local hospital only described the skin defect, and the patient himself was not aware of the deformity in his finger contour. We conjecture two possible scenarios behind his trauma. One is delayed tenolysis caused by snake envenomation. A previous study reported that envenomation by snake bite can result in local tissue damage including hemorrhage, edema, and tissue necrosis [6]. It is possible that the bite had caused tendon damage and loss, which could have progressed by the cytotoxic effect of snake envenomation. Particularly, because the tendon structure is less vascular than the surrounding tissue, damage to the tendon is likely to progress rapidly. The other scenario is a mechanical injury caused by the snake bite. There are four species of venomous snakes residing in South Korea: Gloydius brevicaudus, G. saxatilis, G. ussuriensis, and Rhabdophis tigrinus. Their venoms are not very toxic, and systemic symptoms resulting from these snakes are rare; few mortality cases have been reported in the country $[7,8]$. Consequently, it is presumed that after mechanical trauma by snake bite, lack of adequate initial treatment and wound dressing could lead to infection of local tissue. Tissue infection aggravates the injury done to the tendon and causes mallet deformity with the passage of time. Though we could not ascertain the exact mechanism in the present case, we were able to successfully diagnose the delayed mallet deformity using ultrasonography and treat the patient with one-stage reconstruction. Had the patient 
been only provided with soft tissue wound management without proper examination, diagnosis of mallet deformity might have been delayed. Therefore, early suspicion of deep structure injury, proper physical examination, and evaluation of snakebites are essential. especially when the injury occurs in the hand region.

Ultrasonography is proposed as a good modality in dealing with hand injury caused by snake bites, as it is inexpensive and requires only a short learning curve. The technique is useful especially for moving structures like tendons. Further research on other animal bites on hands causing envenomation is also imperative. Because hand structures are concentrated in small areas and have low vascularity, damage can spread quickly to surrounding structures and lead to extreme consequences, even amputation.

Herein, we present a case of a patient with delayed tendinous mallet finger due to snakebite and treatment thereof, with appropriate diagnosis and one-stage surgical treatment. Envenomation by snake bites can cause local tissue damage and loss of important structure; therefore, diagnosis and proper management in the acute stage is crucial.

\section{Conflict of interest}

No potential conflicts of interest relevant to this article are reported.

\section{Acknowledgments}

Hee Yong Kang https://orcid.org/0000-0002-9902-0604

Eun Soo Park https://orcid.org/0000-0003-2966-9122

Seung Min Nam https://orcid.org/0000-0001-7865-5013

\section{References}

1. Russell FE. Snake venom poisoning in the United States. Annu Rev Med 1980;31:247-59.

2. Shin CS, Bae JS, Sohn KS. Clinical analysis on venomous snake bite in Korea. J Korean Surg Soc 1984;27:245-54.

3. Jiang B, Wang P, Zhang Y, et al. Modification of the internal suture technique for mallet finger. Medicine (Baltimore) 2015; 94:e536.

4. de Silva HJ, Kasturiratne A, Pathmeswaran A, et al. Snakebite: the true disease burden has yet to be determined. Ceylon Med J 2013;58:93-5.

5. Williams D, Gutierrez JM, Harrison R, et al. The global snake bite initiative: an antidote for snake bite. Lancet 2010;375:89-91.

6. Gutierrez JM, Rucavado A, Chaves F, et al. Experimental pathology of local tissue damage induced by Bothrops asper snake venom. Toxicon 2009;54:958-75.

7. Rha JH, Kwon SM, Oh JR, et al. Snakebite in Korea: a guideline to primary surgical management. Yonsei Med J 2015;56:14438.

8. Jang IS, Lee JA, Kim SY, et al. Clinical features in snake bite. J Korean Soc Emerg Med 1996;7:580-9. 